\title{
Risk of low serum levels of ionized magnesium in children with febrile seizure
}

\author{
Sung-Jin Baek, Jung Hye Byeon, So-Hee Eun, Baik-Lin Eun and Gun-Ha Kim
}

\begin{abstract}
Background: Suboptimal intake of magnesium become prevalent due to the modern diet of processed food low in magnesium. Magnesium may modulate seizure activity by antagonizing excitatory calcium influx through the Nmethyl-D-aspartate receptor. Although hyponatremia has been reported to be common in febrile seizures, the most common form of seizure, little is known about the status of serum ionized magnesium. We therefore investigated the status of serum ionized magnesium ( $\mathrm{Mgg}^{2+}$ ) in children with febrile seizures and compared with controls.

Methods: We included all patients from 1 to 6 years old who had presented with febrile seizure to the pediatric emergency department at the Korea University Guro Hospital from July 2016 to February 2017. The control group comprised patients admitted to the hospital with febrile respiratory tract infections, but with no history of febrile seizure. Clinical data, blood tests, and electroencephalogram (EEG) results were reviewed using the patients' medical records.

Results: A total of 133 patients with febrile seizure and 141 control patients were analyzed in the present study. As a result, hypomagnesemia $(<0.50 \mathrm{mmol} / \mathrm{L})$ was more common in patients with febrile seizure than in controls $(42.9 \%$ vs. $6.9 \%, p<0.001)$ and it was an independent risk factor for febrile seizure $(\mathrm{OR}$, odds ratio $=22.12,95 \% \mathrm{Cl}=9$. 23-53.02, $P<0.001)$. A receiver operating curve analysis revealed that serum $\mathrm{img}^{2+}$ levels $<0.51 \mathrm{mmol} / \mathrm{L}$ predicted the presence of febrile seizures with a sensitivity of $45.1 \%$ and a specificity of $92.6 \%$ (AUC, area under the curve $=0.731$, $95 \%$ confidence interval $=0.671-0.791$ ). When the patients with febrile seizure were divided in terms of a serum $\mathrm{iMg}^{2+}$ concentration of $0.51 \mathrm{mmol} / \mathrm{L}$, there was no difference in clinical features.
\end{abstract}

Conclusions: Hypomagnesemia was more common and serum i $\mathrm{Mg}^{2+}$ level was lower in patients with febrile seizures than in controls. However, further evidence is needed for the causal relationship between low magnesium and febrile convulsions.

Keywords: Seizure, Epilepsy, Magnesium, Child, Febrile

\section{Background}

Magnesium is obtained from whole grains, nuts, and green leafy vegetables. However, global diet trends are moving towards high consumption of low-magnesium processed food [1, 2]. People who eat such diets are more likely to develop a magnesium deficiency, as are those who cook or boil all foods-especially vegetables, those who drink soft water, and those who eat food grown in magnesium-deficient soils, where synthetic fertilizers containing no magnesium are often used [1]. Furthermore, magnesium content can be reduced by $82-$

\footnotetext{
* Correspondence: gunhaaa@korea.ac.kr; wjcwife@naver.com Department of Pediatrics, Korea University College of Medicine, Seoul, South Korea
}

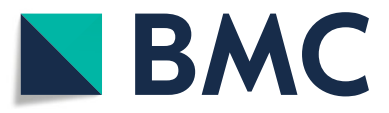

(c) The Author(s). 2018 Open Access This article is distributed under the terms of the Creative Commons Attribution 4.0 International License (http://creativecommons.org/licenses/by/4.0/), which permits unrestricted use, distribution, and reproduction in any medium, provided you give appropriate credit to the original author(s) and the source, provide a link to the Creative Commons license, and indicate if changes were made. The Creative Commons Public Domain Dedication waiver (http://creativecommons.org/publicdomain/zero/1.0/) applies to the data made available in this article, unless otherwise stated.

97\% during the refining and processing of wheat to flour, rice to polished rice, or corn to starch [3]. In fact, large population surveys have shown that suboptimal magnesium intake is widespread [4-7] and that this may have a negative impact on human health.

Magnesium may modulate seizure activity by antagonizing excitatory calcium influx through the N-methyl-D-aspartate (NMDA) receptor [8-11]. Indeed, animal studies have shown that magnesium deficiency is related to increased seizure activity [12-14]. Magnesium sulfate has long been used to prevent eclampsia: a convulsive phase that follows pre-eclampsia in pregnant women, and recent studies have reported that magnesium can be used to treat several human epilepsies [15-17]. In febrile seizure, which afflicts 2- 
$5 \%$ of the pediatric population and is the most common seizure disorder in children [18], only one third of patients have a positive family history of febrile seizure or epilepsy [19], and the majority of patients with febrile seizure have no evident risk factors. Although magnesium deficiency is fairly common, clinicians rarely test for or correctly measure it in patients with febrile seizure.

Clinicians can use the magnesium loading test to evaluate the body's magnesium stores correctly [20, 21]. The preferred test is ionized magnesium instead of total magnesium, because less than $1 \%$ of the body's magnesium is present extracellularly $[22,23]$.

In the present study, we hypothesized that serum magnesium levels could be lower in children with febrile seizures, the most common form of seizure, than in controls. Although hyponatremia has been reported to be common in febrile seizures, little is known about the status of serum ionized magnesium. We therefore investigated the status of serum ionized magnesium $\left(\mathrm{iMg}^{2+}\right)$ in children with febrile seizures and compared with controls.

\section{Methods}

\section{Patients and materials}

The present study included all patients with febrile seizure between 1 and 6 years old who had presented to the pediatric emergency department at the Korea University Guro Hospital for 7 consecutive months from July 2016 to February 2017. Febrile seizure was described by caregivers as a convulsive event that was accompanied by fever (body temperature above $38{ }^{\circ} \mathrm{C}$ ) in the hospital. We excluded patients with a history of afebrile seizures or an abnormal electroencephalography (EEG), as well as those whose $\mathrm{iMg}^{2+}$ levels had not been checked. Of the 152 patients who were screened, we excluded 10 who had a history of unprovoked seizure, one with abnormal EEG results, and eight whose serum $\mathrm{iMg}^{2+}$ level had not been checked. Overall, 133 patients were allocated into the febrile seizure group.

As a control group, we recruited consecutive patients who had been admitted with a febrile respiratory tract infection during the study period and whose serum iMg + levels had been checked. We gathered patients' information and laboratory data using their medical records. Their levels of biochemical and hematologic analytes were included in the laboratory analysis. Serum $\mathrm{iMg}^{2+}$ levels were measured using the NOVA CRT8 analyzer (NOVA biomedical, USA).

\section{Statistical analysis}

Data are presented as medians with inter-quartile ranges for non-normally distributed variables and as means \pm standard deviations for normally distributed continuous variables. We used the student's $t$-test for normally distributed variables, whereas the Mann-Whitney's U-test was used for non-normally distributed variables to compare demographic and laboratory data between the febrile seizure and control groups. To assess the independent predictors of febrile seizure, univariate and multivariate logistic regression analyses were performed, with the results expressed as an odds ratio (OR) with a $95 \%$ confidence interval (CI). The diagnostic value of serum $\mathrm{iMg}^{2+} \mathrm{con}-$ centration was assessed using the area under the receiver operating characteristic (ROC) curve. All $p$-values less than 0.05 were considered statistically significant. Statistical analyses were performed using SPSS version 22.0 (IMB SPSS Inc., New York, United States).

\section{Results}

Characteristics of patients with simple febrile seizure The characteristics of the febrile seizure group are shown in Table 1 (total: 133; 73 boys and 60 girls). Nine of these patients $(6.8 \%)$ had multiple seizure episodes (five had two episodes and four had three episodes). Nineteen of the patients (14.3\%) had a family history of febrile seizure, and four had a developmental delay (two motor and two language delays).

\section{Comparison of laboratory values}

One-hundred forty-one control patients who had been admitted with a febrile respiratory tract infection were compared with the 133 patients with febrile seizure (Table 2). Age and sex did not differ between the two groups, nor did the proportion of patients with abnormal laboratory values other than serum sodium and serum $\mathrm{iMg}^{2+}$. Hyponatremia was noted in $21.1 \%$ of the patients in the febrile seizure group and in $5.0 \%$ of those in the control group $(P<0.001)$. Hypomagnesemia was more common in the febrile seizure group than in the control group $(42.9 \%$ vs. $6.9 \%$, respectively; $P<0.001)$.

Table 1 Baseline characteristics of patients with febrile seizure $(n=133)$

\begin{tabular}{ll}
\hline Men/Women & $73(54.9) / 60(45.1)$ \\
Age (year) & $2.1[1.7-3.1]$ \\
Family history of febrile seizure epilepsy & $19(14.3) / 1(0.8)$ \\
Past history of febrile convulsion & $40(30.1)$ \\
Developmental delay & $4(3.0)$ \\
Mean seizure duration (minute) & $2.37 \pm 2.20$ \\
Seizure longer than 15 min & $0(0)$ \\
Multiple seizure episodes & $9(6.8)$ \\
Seizure type (Focal/Generalized) & $0(0) / 133(100)$ \\
\hline
\end{tabular}

Data are presented as medians [inter-quartile ranges] for non-normally distributed variables, as means \pm standard deviations for all normally distributed continuous variables, and as $n(\%)$ in the case of countable variables. $n$, number of patients 
Table 2 Difference in laboratory data between patients with febrile seizures and control patients

\begin{tabular}{|c|c|c|c|}
\hline Group & Febrile seizure $(n=133)$ & Control $(n=141)$ & $P$-value \\
\hline Age (year) & $2.1[1.7-3.1]$ & $1.9[1.5-3.0]$ & 0.128 \\
\hline Men/Women & $73(54.9) / 60(45.1)$ & $77(54.6) / 64(45.4)$ & 1.000 \\
\hline Hypocalcemia $^{a}$ & $13(11.6)$ & $14(10.6)$ & 0.763 \\
\hline Hypomagnesemia & $57(42.9)$ & $7(6.9)$ & $<0.001^{*}$ \\
\hline Serum iMg ${ }^{2+}(\mathrm{mmol} / \mathrm{L})$ & $0.5 \pm 0.1$ & $0.6 \pm 0.0$ & \\
\hline Hyponatremia & $28(21.1)$ & $7(5.0)$ & $<0.001^{*}$ \\
\hline Serum $\mathrm{Na}(\mathrm{mmol} / \mathrm{L})$ & $136.0[135.0 ; 137.0]$ & 138.0 [137.0; 139.0] & \\
\hline Hypokalemia & $3(2.3)$ & $5(3.5)$ & 0.783 \\
\hline
\end{tabular}

\section{Predicting independent risk factors for developing febrile seizure}

We performed univariate and multivariate logistic regression analysis to determine independent demographic and laboratory risk factors for developing febrile seizure (Table 3). The analysis revealed that hypomagnesemia and hyponatremia were independent risk factors $(\mathrm{OR}=$ 22.12, 95\% $\mathrm{CI}=9.23-53.02, P<0.001$ and $\mathrm{OR}=4.81$; $95 \% \mathrm{CI}=1.67-13.85, p=0.0036$, respectively).

\section{Hypomagnesemia}

As shown in Fig. 1, serum $\mathrm{iMg}^{2+}$ levels were lower in patients with febrile seizure than in control patients (mean \pm $\mathrm{SD}=1.0 \pm 0.2$ vs. $1.2 \pm 0.1 \mathrm{mEq} / \mathrm{L}$, respectively; $P<0.001$ ) The area under the ROC curve for serum i $\mathrm{Mg}^{2+}$ levels was $0.731(95 \% \mathrm{CI}=0.671-0.791)$, indicating that serum $\mathrm{iMg}^{2+}$ levels of $<0.51 \mathrm{mmol} / \mathrm{L}$ in children predicted the presence of febrile seizures with a sensitivity of $45.1 \%$ and a specificity of $92.9 \%$ (Fig. 2).

As noted in Table 4, we next divided the patients with febrile seizure into two subgroups on the basis of serum $\mathrm{iMg}^{2+}$ levels $(<0.51 \mathrm{mmol} / \mathrm{L}$ and $\geq 0.51 \mathrm{mmol} / \mathrm{L})$. We found no difference between the groups in terms of seizure duration or number of seizure episodes.

\section{Discussion}

In clinical practice, hypomagnesemia is underdiagnosed or incorrectly measured in patients with febrile seizure. People with modern diets are more likely to have low magnesium stores in their body [1-7], and magnesium can modulate seizures [8-14]. For these reasons, it could be beneficial to accurately measure i $\mathrm{Mg}^{2+}$ levels, not total magnesium levels, in patients with febrile seizures.

In the present study, we found that hypomagnesemia and mild hyponatremia were more common in patients with febrile seizure than in those with febrile respiratory tract infection (Fig. 1). Multivariate logistic regression analysis revealed that both hypomagnesemia $(<0.50 \mathrm{mmol} / \mathrm{L})$ and hyponatremia $(<135 \mathrm{mmol} /$ L) were independent risk factors for developing febrile seizure. Since few studies have addressed $\mathrm{iMg}^{2+}$ levels in children, we determined an optimal cut-off value for the occurrence of febrile seizures. An ROC analysis revealed that serum $\mathrm{iMg}^{2+}$ levels $<0.51 \mathrm{mmol} / \mathrm{L}$ in children predicted the presence of febrile seizures with a sensitivity of $45.1 \%$ and a specificity of $92.9 \%$ (area under the ROC curve $=0.731,95 \%$ CI $=0.671-$ 0.791; Fig. 2).

Table 3 Univariate and multivariate analysis of significant risk factors associated with febrile seizure $(n=274)$

\begin{tabular}{|c|c|c|c|c|c|c|}
\hline & \multicolumn{3}{|c|}{ Univariate Analysis } & \multicolumn{3}{|c|}{ Multivariate Analysis } \\
\hline & Crude OR & $95 \% \mathrm{Cl}$ & $P$-value & Adjusted OR & $95 \% \mathrm{Cl}$ & $P$-value \\
\hline Age & 1.09 & $0.89-1.34$ & 0.4189 & & & \\
\hline Sex & 0.99 & $0.61-1.59$ & 0.9632 & & & \\
\hline Hypocalcemia & 1.23 & $0.55-2.75$ & 0.6120 & & & \\
\hline Hypomagnesemia & 14.36 & $6.24-33.05$ & $<0.001$ & 22.12 & $9.23-53.02$ & $<0.001$ \\
\hline Hyponatremia & 5.10 & $2.15-12.14$ & 0.0002 & 4.81 & $1.67-13.85$ & 0.0036 \\
\hline Hypokalemia & 0.63 & $0.15-2.68$ & 0.5294 & & & \\
\hline
\end{tabular}

Normal pediatric ranges as follows: Ca $(9.2-10.6 \mathrm{mg} / \mathrm{dL}), \mathrm{iMg}^{2+}(0.50-0.70 \mathrm{mmol} / \mathrm{L}), \mathrm{Na}(135-145 \mathrm{mmol} / \mathrm{L})$, and $\mathrm{K}(3.6-5.2 \mathrm{mmol} / \mathrm{L}) . \mathrm{n}, \mathrm{number}$ of patients; OR, odds ratio; $\mathrm{Cl}$, confidence interval; i $\mathrm{Mg}^{2+}$, lonized magnesium 


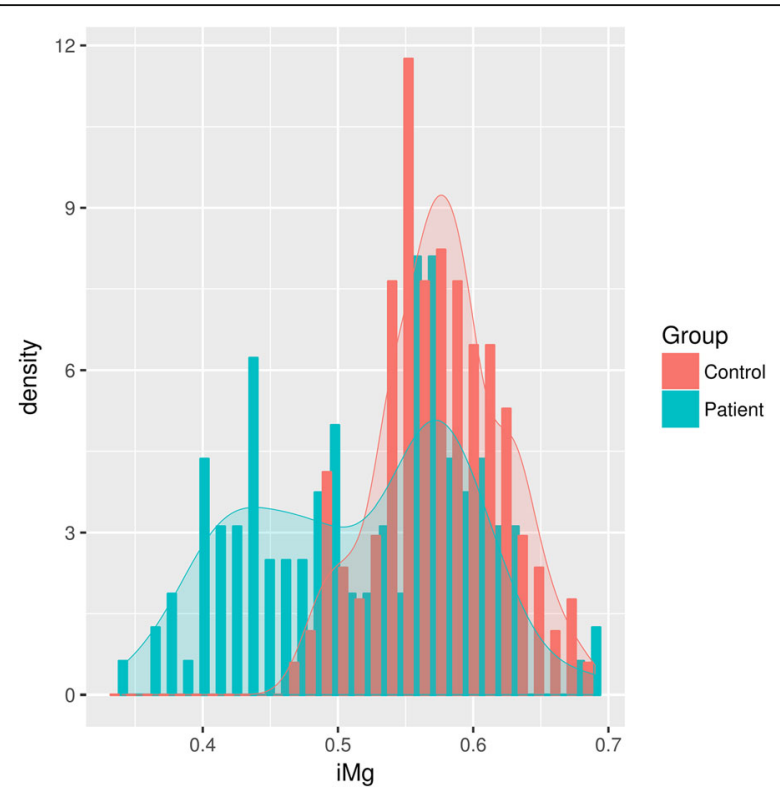

Fig. 1 Density plot graphic of serum $\mathrm{iMg}^{2+}$ levels in the patients with febrile seizures and in controls. Serum i $\mathrm{Mg}^{2+}$ levels in patients with febrile seizures are lower than in control patients (mean \pm SD: $0.5 \pm 0.1$ vs. $0.6 \pm 0.0 \mathrm{mmol} / \mathrm{L}$, respectively; $P<0.001$ )

\section{Literature about hyponatremia and hypomagnesemia in} febrile seizure

Many studies have noted that hyponatremia is common in cases of febrile seizure $[20,21,24-28]$. Besides, several studies have claimed that hyponatremia can predict further seizures [20, 24, 25], while others have contradicted this finding [21, 26-28]. One investigation reported that patients with hyponatremic febrile seizure had increased arginine vasopressin levels on the first day of admission, and that they had decreased sodium and osmolality levels on the second day. These findings suggest that fever and other non-osmotic stimuli lead to excess arginine

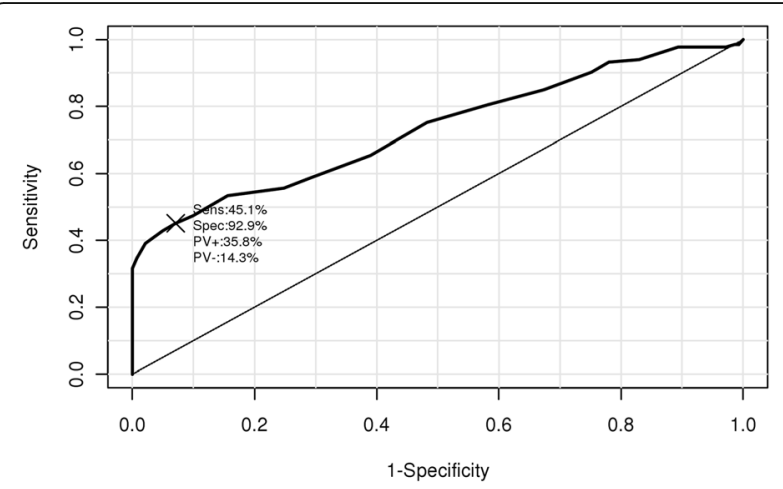

Fig. 2 Receiver operating curve analysis of serum i $\mathrm{Mg}^{2+}$ levels in the febrile seizure and control groups (cut-off level: $0.51 \mathrm{mmol} / \mathrm{L}$, sensitivity: $45.1 \%$, specificity: $92.9 \%$; area under curve: $0.731,95 \%$ confidence interval: 0.671-0.791). Sens, sensitivity; Spec, specificity; $\mathrm{PV}+$, positive predictive value; PV-, negative predictive value vasopressin, causing transient mild hyponatremia [29]. Mild hyponatremia in our study was usually measured immediately after febrile seizure in the emergency room, thus, which is thought to be due to febrile illness or mild dehydration rather than excessive arginine vasopressin secretion.

For hypomagnesemia, only one previous investigation related to febrile seizure reported that hypomagnesemia was noted in $86 \%$ of patients with simple febrile seizure [30]. However, the study has limited value because of that they measured the total magnesium rather than the $\mathrm{Mgg}^{2+}$ concentration in the blood and did not involve a control group.

\section{Anti-seizure effect of magnesium}

It may be that magnesium acts as an anticonvulsant because it modulates seizure activity by antagonizing excitatory calcium influx through the NMDA receptors [31-34].

In particular, magnesium sulfate increases the seizure threshold without affecting the permeability of the bloodbrain barrier in a rat model of severe pre-eclampsia [35]. A single oral dose of magnesium can inhibit NMDA-induced convulsions in mice in a dose-dependent manner [34], and Continuous intravenous magnesium infusion reduced seizures in one of two patients with fever-related epilepsy syndrome [16]. Furthermore, in patients with infantile spasms, combined treatment using adrenocorticotropic hormone and intravenous magnesium sulfate yielded a better response than treatment using adrenocorticotropic hormone alone (79\% vs. 53\%) [17]. Finally, one study found that oral magnesium was an effective adjunct treatment for medically intractable epilepsies [36], reporting that $36 \%(8 / 22)$ of the patients saw $a \geq 75 \%$ reduction in the number of seizure days per month after a follow-up of 6-12 months.

\section{Measurement of physiologically active magnesium concentration}

Most magnesium is stored within bones (50\%) and soft tissues (47\%), while less than $1 \%$ of total body magnesium is present in blood, with approximately $0.3 \%$ in serum $[22,23]$. Thus, clinicians should use the magnesium loading test to evaluate the body's magnesium stores correctly $[20,21]$ or measure the free, ionized form of magnesium, which is physiologically active. One study found that, in $25 \%$ of patients, biologically active levels of $\mathrm{iMg}^{2+}$ were not reflected in an analysis of total magnesium, and that $\mathrm{iMg}^{2+}$ was only weakly correlated with total magnesium [37].

In 1992, Altura et al. designed a novel ion selective electrode that utilizes a neutral carrier-based membrane to assess i $\mathrm{Mg}^{2+}$ in whole blood, plasma, and serum [38], so i $\mathrm{Mg}^{2+}$ levels can now be easily measured. Nevertheless, most clinical laboratories still measure total magnesium levels using colorimetry or atomic absorption spectrophotometry. 
Table 4 Comparison of clinical variables according to ionized magnesium level among patients with febrile seizure

\begin{tabular}{llll}
\hline Variables & \multicolumn{2}{l}{ Serum levels of ionized $\mathrm{Mg}^{2+}$} & \\
\cline { 2 - 3 } & $<0.51 \mathrm{mmol} / \mathrm{L}(n=60)$ & $\geq 0.51 \mathrm{mmol} / \mathrm{L}(n=73)$ & $40(54.8) / 33(45.2)$ \\
\hline Men/Women & $33(55.0) / 27(45.0)$ & $2.1[1.7 ; 3.0]$ & 1.000 \\
Age (year) & $2.2[1.7 ; 3.4]$ & $1(1.4)$ & 0.741 \\
Family history of epilepsy & 0 & $9(12.3)$ & 1.000 \\
Family history of FS & $10(16.7)$ & $22(30.1)$ & 0.644 \\
Past history of FS & $18(30.0)$ & $4(5.5)$ & 1.000 \\
Developmental delay & 0 & $4(5.5)$ & 0.183 \\
Multiple seizure episodes & $5(8.3)$ & $1.0[1.0 ; 3.0]$ & 0.760 \\
Seizure duration (min) & $2.0[1.0 ; 3.0]$ & $5(6.8)$ & 0.366 \\
Seizure longer than 5 min & $2(3.3)$ & 0.608
\end{tabular}

Data are presented as medians [inter-quartile ranges] for non-normally distributed variables, as means \pm standard deviations for all normally distributed continuous variables, and as $\mathrm{n}(\%)$ in the case of countable variables. $n$, number of patients; FS, febrile seizure

\section{Reference interval of ionized magnesium level}

The $\mathrm{iMg}^{2+}$ level varies according to the analytical method, instrument type, matrix, and reagent composition used [39]. Several reports have estimated the reference interval of $\mathrm{iMg}^{2+}$ in adults using the NOVA CRT8. The mean $\mathrm{iMg}^{2+}$ level in healthy Canadian adults was 0.52 (range: $0.44-0.59$ ) $\mathrm{mmol} / \mathrm{L}$ in whole blood [40], while it was $0.57 \pm 0.03$ (range: $0.51-0.63$ ) $\mathrm{mmol} / \mathrm{L}$ in Japanese adults. However, only a few reports have measured $\mathrm{Mgg}^{2+}$ levels in children using the NOVA CRT8. One by Hoshiono et al. involved 160 healthy Japanese children and found that the mean $\mathrm{iMg}^{2+}$ level was 0.53 \pm 0.03 (range: $0.45-0.63$ ) $\mathrm{mmol} / \mathrm{L}$ [41] .

Our study had several limitations. By selecting patients with respiratory infections with fever as a control group, it is advantageous to eliminate the effects of fever on magnesium concentrations in the blood. However, it is also meaningful to compare three groups, including healthy controls. Furthermore, when analyzing the risk factors for febrile seizure, we assumed that the magnesium concentration after the seizure was the same as that before. However, this may not have been the case.

\section{Conclusions}

Hypomagnesemia was more common and serum iMg ${ }^{2+}$ levels were lower in patients with febrile seizures than in controls. However, further evidence is needed for the causal relationship between low magnesium and febrile convulsions.

\section{Abbreviations}

EEG: Electroencephalography; iMg ${ }^{2+}$ : lonized magnesium; NMDA: N-methylD-aspartate

\section{Availability of data and materials}

The datasets during and/or analysed during the current study available from the corresponding author on reasonable request.

\section{Authors' contributions}

GHK conceived of the study, and SHE and BLE conceived of its design. SJB and JHB acquired and performed the data analysis activities. GHK, JHB, SHE,
BLE, and SJB interpreted the data, wrote and edited the manuscript, and have approved it for submission.

\section{Ethics approval and consent to participate}

This study was approved by the Institutional Review Board at Korea University College of Medicine (KUGH16178), and the need for written informed consent was waived.

\section{Consent for publication}

Not applicable

Competing interests

The authors declare that they have no competing interests.

\section{Publisher's Note}

Springer Nature remains neutral with regard to jurisdictional claims in published maps and institutional affiliations.

Received: 1 February 2018 Accepted: 30 August 2018

Published online: 07 September 2018

\section{References}

1. Wilkinson S, Stuedemann J, Grunes D, Devine O. Relation of soil and plant magnesium to nutrition of animals and man. Magnesium. 1987;6(2):74.

2. Rosanoff A. Changing crop magnesium concentrations: impact on human health. Plant Soil. 2013;368(1-2):139-53.

3. Chaudhary DP, Sharma R, Bansal DD. Implications of magnesium deficiency in type 2 diabetes: a review. Biol Trace Elem Res. 2010;134(2):119-29.

4. Pennington J, Schoen S. Total diet study: estimated dietary intakes of nutritional elements, 1982-1991. Int J Vitam Nutr Res. 1996;66(4):350-62.

5. Galan P, Preziosi P, Durlach V, Ribas L, Bouzid D, Fieux B, Favier A, Hercberg S. Dietary magnesium intake in French adult population. In: Magnesium: current status and new developments. Dordrecht: Springer; 1997. p. 147-49.

6. Ford ES. Race, education, and dietary cations: findings from the third National Health and Nutrition Examination Survey. Ethn Dis. 1998;8(1):10-20.

7. Ford ES, Mokdad AH. Dietary magnesium intake in a national sample of US adults. J Nutr. 2003;133(9):2879-82.

8. Ault B, Evans R, Francis A, Oakes D, Watkins J. Selective depression of excitatory amino acid induced depolarizations by magnesium ions in isolated spinal cord preparations. J Physiol. 1980;307(1):413-28.

9. Coan E, Collingridge G. Magnesium ions block an N-methyl-D-aspartate receptor-mediated component of synaptic transmission in rat hippocampus. Neurosci Lett. 1985:53(1):21-6.

10. Cotton DB, Hallak M, Janusz C, Irtenkauf SM, Berman RF. Central anticonvulsant effects of magnesium sulfate on N-methyl-D-aspartateinduced seizures. Am J Obstet Gynecol. 1993;168(3):974-8.

11. Hallak M. Effect of parenteral magnesium sulfate administration on excitatory amino acid receptors in the rat brain. Magnes Res. 1998;11(2):117-31. 
12. Walther H, Lambert J, Jones R, Heinemann U, Hamon B. Epileptiform activity in combined slices of the hippocampus, subiculum and entorhinal cortex during perfusion with low magnesium medium. Neurosci Lett. 1986;69(2): 156-61.

13. Cao H-Y, Jiang Y-W, Liu Z-W, Wu X-R. Effect of recurrent epileptiform discharges induced by magnesium-free treatment on developing cortical neurons in vitro. Dev Brain Res. 2003;142(1):1-6.

14. Siniscalchi A, Calabresi P, Mercuri N, Bernardi G. Epileptiform discharge induced by 4-aminopyridine in magnesium-free medium in neocortical neurons: physiological and pharmacological characterization. Neuroscience. 1997;81(1):189-97.

15. Visser NA, Braun KP, Leijten FS, van Nieuwenhuizen O, Wokke JH, van den Bergh WM. Magnesium treatment for patients with refractory status epilepticus due to POLG1-mutations. J Neurol. 2011;258(2):218-22.

16. Tan WW, Chan DW, Lee JH, Thomas T, Menon AP, Chan YH. Use of magnesium sulfate infusion for the management of febrile illness-related epilepsy syndrome: a case series. Child Neurology Open. 2015;2(1):2329048X14550067.

17. Zou L-P, Wang X, Dong C-H, Chen C-H, Zhao W, Zhao R-Y. Three-week combination treatment with $\mathrm{ACTH}+$ magnesium sulfate versus $\mathrm{ACTH}$ monotherapy for infantile spasms: a 24-week, randomized, open-label, follow-up study in China. Clin Ther. 2010;32(4):692-700.

18. Waruiru C, Appleton R. Febrile seizures: an update. Arch Dis Child. 2004; 89(8):751-6.

19. Verity C, Butler N, Golding J. Febrile convulsions in a national cohor followed up from birth. I--prevalence and recurrence in the first five years of life. Br Med J (Clin Res Ed). 1985;290(6478):1307-10.

20. Kiviranta T, Airaksinen E. Low sodium levels in serum are associated with subsequent febrile seizures. Acta Paediatr. 1995;84(12):1372-4.

21. Thoman JE, Duffner PK, Shucard JL. Do serum sodium levels predict febrile seizure recurrence within 24 hours? Pediatr Neurol. 2004;31(5):342-4.

22. Elin R. Laboratory tests for the assessment of magnesium status in humans. Magnes Trace Elem. 1990;10(2-4):172-81.

23. Long S, Romani AM. Role of cellular magnesium in human diseases. Austin $J$ Nutr Food Sci. 2014;2:(10):1051.

24. Hugen C, Oudesluys-Murphy A, Hop W. Serum sodium levels and probability of recurrent febrile convulsions. Eur J Pediatr. 1995;154(5):403-5.

25. Nadkarni J, Binaykiya I, Sharma U, Dwivedi R. Role of serum sodium levels in prediction of seizure recurrence within the same febrile illness. Neurology Asia. 2011;16(3):195-7.

26. Heydarian F, Ashrafzadeh F, Kam S. Simple febrile seizure: the role of serum sodium levels in prediction of seizure recurrence during the first 24 hours. Iranian J Child Neurol. 2009;3(2):31-4.

27. Maksikharin A, Prommalikit O. Serum sodium levels do not predict recurrence of febrile seizures within 24 hours. Paediatr Int Child Health. 2015;35(1):44-6

28. Chou H-F, Shen E-Y, Kuo Y-T. Utility of laboratory tests for children in the emergency department with a first seizure. Pediatr Emerg Care. 2011;27(12): 1142-5.

29. Hasegawa H, Okubo S, Ikezumi Y, Uchiyama K, Hirokawa T, Hirano H, Uchiyama M. Hyponatremia due to an excess of arginine vasopressin is common in children with febrile disease. Pediatr Nephrol. 2009;24(3):507.

30. Bharathi S, Chiranjeevi K. Study of serum magnesium levels and its correlation with febrile convulsions in children aged 6 months to 5 years of age. IAIM. 2016;2(11):61-68.

31. Hallak M, Berman RF, Irtenkauf SM, Janusz CA, Cotton DB. Magnesium sulfate treatment decreases $\mathrm{N}$-methyl-D-aspartate receptor binding in the rat brain: an autoradiographic study. J Soc Gynecol Investig. 1994;1(1):25-30.

32. Dingledine R, Hynes MA, King GL. Involvement of N-methyl-D-aspartate receptors in epileptiform bursting in the rat hippocampal slice. J Physiol. 1986;380(1):175-89.

33. Euser AG, Cipolla MJ. Magnesium sulfate for the treatment of eclampsia. Stroke. 2009:40(4):1169-75

34. Decollogne S, Tomas A, Lecerf C, Adamowicz E, Seman M. NMDA receptor complex blockade by oral administration of magnesium: comparison with MK-801. Pharmacol Biochem Behav. 1997;58(1):261-8.

35. Johnson AC, Tremble SM, Chan S-L, Moseley J, LaMarca B, Nagle KJ, Cipolla MJ. Magnesium sulfate treatment reverses seizure susceptibility and decreases neuroinflammation in a rat model of severe preeclampsia. PLoS One. 2014;9(11):e113670.

36. Abdelmalik PA, Politzer N, Carlen PL. Magnesium as an effective adjunct therapy for drug resistant seizures. Can J Neurol Sci. 2012;39(03):323-7.
37. Johansson M, Whiss PA. Weak relationship between ionized and total magnesium in serum of patients requiring magnesium status. Biol Trace Elem Res. 2007;115(1):13-21.

38. Glasdam S-M, Glasdam S, Peters GH. Chapter six-the importance of magnesium in the human body: a systematic literature review. Adv Clin Chem. 2016;73:169-93.

39. Liu J, Yuan E, Zhang Z, Jia L, Yin Z, Meng X, Du H. Age-and sex-specific reference intervals for blood copper, zinc, calcium, magnesium, iron, lead, and cadmium in infants and children. Clin Biochem. 2012;45(6):416-9.

40. Greenway DC, Hindmarsh JT, Wang J, Khodadeen JA, Hébert PC. Reference interval for whole blood ionized magnesium in a healthy population and the stability of ionized magnesium under varied laboratory conditions. Clin Biochem. 1996;29(6):515-20.

41. Hoshino K, Ogawa K, Kitazawa R, Nakamura Y, Uehara R. lonized magnesium level in whole blood of healthy Japanese children. Pediatr Int. 1998:40(2): $116-21$.

\section{Ready to submit your research? Choose BMC and benefit from:}

- fast, convenient online submission

- thorough peer review by experienced researchers in your field

- rapid publication on acceptance

- support for research data, including large and complex data types

- gold Open Access which fosters wider collaboration and increased citations

- maximum visibility for your research: over $100 \mathrm{M}$ website views per year

At $\mathrm{BMC}$, research is always in progress.

Learn more biomedcentral.com/submissions 